\title{
Simultaneous estimation of risk and time preferences among small- scale cattle farmers in West Africa
}

\author{
SABINE LIEBENEHM AND HERMANN WAIBEL
}

\begin{abstract}
This study investigates risk and time preferences of small-holder cattle farmers in West Africa. We apply a discounted utility model and jointly estimate a prospect theory-based utility function and a quasi-hyperbolic discounting function using a maximum likelihood method. Results show that West African farmers are less lossaverse and are more patient than suggested by comparable studies in Asian developing countries. The main factors influencing farmers' risk and time preferences are cattle herd size and net revenue from sales of cattle products.
\end{abstract}

Key words experiments, prospect theory, risk preference, time preference, West Africa

\section{Acknowledgements}

We are grateful to Glenn W. Harrison who provided us with statistical codes and gave valuable comments on the design of the maximum likelihood program. We are also grateful for the inspiring discussion of results at the PEGNet Conference in 2011 and at the Annual International Conference of the German Economic Association in 2012. The project is financed by the German research foundation grant number WA 1002/81. 
In West Africa, smallholder pastoralist systems are a major source of people's livelihood. Livestock diseases, especially the African animal trypanosomosis (AAT), are one of the major threats to these mostly poor households. The costs of AAT are estimated at US\$1.3 billion annually, due to forgone milk and meat production (Kristjanson et al. 1999). In areas with high AAT prevalence pastoralist households have to face a reduction in food production by $25 \%$ (Agyemang et al. 1991).

Trypanocidal drugs are most frequently used to manage instances of AAT. Trypanocides can be applied ex ante as a preventive strategy and ex post as a curative strategy upon the emergence of disease symptoms. In most cases trypanocides are administered by cattle farmers and not by trained veterinarians leading to frequent cases of misuse. The misguided use of trypanocides has led to the widespread resistance of AAT strains to trypanocides (Clausen et al. 2010; Grace et al. 2009).

In principal, farmers have to make a choice between preventive and curative trypanocide treatments. Against experts' recommendations most farmers decide on curative treatments (Liebenehm, Affognon, and Waibel 2011). Curative measures are cheaper, though have a lower probability of success. However, preventive measures are more expensive, show lower risk of failing but have later payback (Mungube, 2010). Hence, risk and time preferences are two critical behavioral variables that influence the treatment decision and may explain, in part, why the spread of the disease cannot be contained. 
The objectives of this article are to simultaneously assess the risk and time preferences of small-scale cattle farmers in West Africa and to examine how preferences are related to demographic and socio-economic characteristics.

In order to achieve these objectives we use a data set that combines economic field experiments conducted in 2011 with household panel survey among cattle farmers in West Africa for three periods from 2003/2004, 2007 and 2011. The experiments yield information on cattle farmers risk and time preferences whilst the panel data allows a $\mathrm{n}$ analysis of the correlation between the two decision variables and decision outcomes.

To explain cattle farmer behavior we develop a discounted utility model. A quasihyperbolic discounting function is used to estimate the present value of future utility streams. We define a farmer's utility function based on prospect theory (Kahneman and Tversky 1979; Tversky and Kahneman 1992) so as to capture risk in gain and loss situations, and the respondents' weighting of probabilities. A discounted utility model allows us to explain the dynamic decision making behavior of cattle farmers under uncertainty. Such an understanding is vital for the development of solutions to a problem, which constrains the safety net function of cattle health for pastoralists (Fafchamps, Udry, and Czukas 1998).

The model is formulated as a structural estimation approach introduced by Harrison and Rutström (2008). The parameters of the model are simultaneously estimated using the maximum likelihood technique. 
Our article is complementary to the recent study of Tanaka, Camerer and Nguyen (2010) who conducted risk and time experiments with rural villagers in Vietnam and found that wealthier villagers are less loss averse and more patient.

Our article establishes empirical evidence for a different socio-economic and ecological environment: smallholder pastoralist systems in the West African cotton zone. The main difference in our findings, as compared to the Asian study, is that wealthier farmers are less risk averse and less patient. We believe that our article adds to the literature in two ways. First, we add a new regional perspective for one of the poorest areas in the world and second, we construct a discounted utility model which simultaneously estimates the parameters of risk and time preferences.

In the next section we provide the conceptual framework, while section three presents the methodology used to measure risk and time as well as the identification of factors that can explain variation thereof. Data collection and the design of the economic field experiments are described in section four with the main findings discussed in section five. The results are split into two parts, namely results from a descriptive analysis and secondly results from the structural analysis. Finally, in section six we draw some conclusions which we believe are relevant for policy and we identify additional research needs.

\section{Conceptual framework}

Economic field experiments exploring people's risk preferences in developing countries have a long tradition, starting with Binswanger $(1980 ; 1981)$. In more recent studies risk and time preferences have been jointly elaborated. Most of these studies 
were carried out in developed countries, e.g. Denmark (Andersen et al. 2008) or Japan (Ida and Goto 2009).

One study that jointly explores risk and time preferences carried out in the developing world is that of Tanaka, Camerer and Nguyen (2010), who conducted experiments with rural villagers in Vietnam. They expanded the measurements of risk preferences beyond the concavity of the utility function and incorporated gains and losses through employing prospect theory (Kahneman \& Tversky 1979; Tversky \& Kahneman 1992). In their time discounting model Tanaka, Camerer and Nguyen (2010) use a generalized function that nests hyperbolic and exponential specifications as recommended by Benhabib, Bisin and Schotter (2010). In a cross-sectional study, in order to infer causality from correlation between observed behavior in the experiments and outcomes from real world decision behavior observed in the living standard survey Tanaka, Camerer and Nguyen (2010) applied an instrumental variable approach. Their results show that subjects from wealthy villages were likely to be less risk averse towards gains and losses. Household and mean village incomes were found to correlate with lower discount rates, i.e. individuals living in wealthy villages were more patient. Tanaka, Camerer and Nguyen (2010) also found that villagers associated a discrete cost to the future reward regardless of their wealth.

In this study we contribute to the methods of joint elaboration of risk and time preferences. We merge the two theoretical components of risk and time preferences and develop a common discounted utility model in order to estimate the present value of utility streams. The advantage of such an incorporated model is that it is not 
necessary to make any assumptions about the concavity of preferences (Harrison and Rutström 2008; Andersen et al. 2008).

Our discounted utility model comprises two main components, i.e. risk and time preferences that are elaborated in the following.

\section{Risk preferences}

Most studies on risk preferences use expected utility theory and implicitly assume that risk aversion comes solely from the concavity of a subject's utility function (Binswanger 1980; Wik et al. 2004; Brick, Visser, and Burns 2012; Hardeweg, Menkhoff, and Waibel forthcoming).

Tversky and Kahneman's $(1979 ; 1992)$ prospect theory is an expansion of expected utility theory in two ways: (i) the differentiation in the value of gains and losses, and (ii) the weighting of outcome probabilities. In the case of West African cattle farmers at risk of losing their animals to diseases it is necessary to differentiate between gains and losses.

Furthermore, we assume that agents (cattle farmers) behave in accordance with cumulative prospect theory (Tversky and Kahneman 1992) and weight outcome probabilities by the one-parameter probability function derived by Prelec (1998). The agent's utility under cumulative prospect theory is then defined as:

$$
P T(x, p ; y, q)=\left\{\begin{array}{cl}
v(y)+w(p)((v(x)-v(y)), & x>y>0 \text { or } x<y<0 \\
w(p) v(x)+w(q)(v(y), & x<0<y
\end{array}\right.
$$


where $P T(x, p ; y, q)$ is the expected value over binary prospects $(x ; y)$ with corresponding probabilities $(p ; q)$. Further, a piecewise power function assigns a value for gains $(x>0)$ and losses $(x<0)$ separately:

$$
v(x)=\left\{\begin{array}{ccc}
x^{\sigma}, & \text { if } & x>0 \\
-\lambda\left(-x^{\sigma}\right), & \text { if } & x<0
\end{array}\right. \text {. }
$$

The parameter $\sigma$ is a proxy for risk aversion ${ }^{\mathrm{i}}$ and $\lambda$ reflects the degree of loss aversion. It is hypothesized that $v(x)$ is s-shaped, i.e. concave above the reference point, convex below the reference point, and also steeper for losses than for gains (Tversky and Kahneman 1992).

Prelec's (1998) probability weighting function that is axiomatically derived is:

$$
w(p)=\frac{1}{\exp (\ln (1 / p))^{\alpha}},
$$

where $\alpha$ presents a proxy for probability weighting. It is hypothesized that $w(p)$ is inverted s-shaped, i.e. a subject overweight small probabilities and underweight large probabilities.

The above specification of a utility model under prospect theory nests the expected utility model. The expected utility specification is obtained if $\alpha=1$ and $\lambda=1$.

\section{Time preferences}

The second theoretical component of our discounted utility model is time preferences. In many studies on time preferences it has been observed that decision makers' behavior is not consistent with exponential discounting (Frederick, Loewenstein, and O’Donoghue 2002; Green, Myerson, and McFadden 1997; Laibson 1997; Loewenstein and Prelec 1992; Thaler and Shefrin 1981). For example, subjects who 
reject a higher reward tomorrow in favor of immediately obtaining a smaller reward, reverse their behavior when the delay of both rewards is increased by a constant amount. Another pattern observed is the so called 'magnitude effect', i.e. the higher the discounted reward is, the smaller is the rate of discounting.

Benhabib, Bisin and Schotter's (2010) discounting model is adequate to reproduce the reversal of preferences over time and the magnitude effect. Their general model expands exponential discounting in the way that it includes hyperbolic specification and various forms of present bias, i.e. when the decision maker has the choice between an immediate and a delayed reward they associate a discrete cost to the reward that is obtained in the future.

Following Laibson (1997) and O'Donoghue and Rabin (1999), we apply the quasihyperbolic specification ${ }^{\mathrm{ii}}$, where the future reward is associated with a cost that is proportional to the amount of the reward. Formally, the discount factor is defined for the present $(t=0)$ and for the delayed rewards $(t>0)$ as:

$$
D(\beta, \delta, t)=\left\{\begin{array}{cc}
1, & \text { if } t=0 \\
\beta \exp (-\delta t), & \text { if } t>0
\end{array},\right.
$$

where $\beta$ is the parameter reflecting present biasedness and $\delta$ represents the parameter of time preference. It is hypothesized that subjects living in a poor environment, such as our small-holder pastoralists, are generally less patient as has been found in many other studies (e.g. Fisher 1930; Pender 1996; Nielsen 2001; Harrison, Lau, and Williams 2002; Anderson et al. 2004). 
We constitute our discounted utility model by incorporating the utility function under prospect theory and the quasi-hyperbolic discounting function into an additive utility function:

$$
U\left(x_{1}, t_{1} ; \ldots ; x_{n}, t_{n}\right)=\sum_{i=1}^{n} P T\left(x_{i}\right) D\left(t_{i}\right)
$$

where the preferences over the temporal prospects $\left(x_{i}, t_{i}\right)$ are intertemporal separable (Loewenstein and Prelec 1992).

In total, there are five parameters in our discounted utility model that need to be jointly estimated:

(i) $\sigma$, which describes the concavity of the value function and is the measure of risk aversion; (ii) $\lambda$, which represents the degree of loss aversion,

(iii) $\alpha$, which presents a proxy for probability weighting,

(iv) $\beta$, which denotes the present biasedness parameter, and

(v) $\delta$, which signifies the subjective discount rate.

The first three parameters are estimated by means of the observations in the risk experiment, while the last two parameters are estimated by means of the time experiment. The design of the experiments is explained in the next section.

\section{Data}

The data used in in our study stems from two sources: (i) economic field experiments conducted in 2011 and (ii) household panel survey over three periods of time.

The field experiments on risk and time preferences had been designed in the form of a 'switching Multiple Price List' (sMPL) design (Andersen et al. 2006). The design has 
been used by, among others, Nguyen and Leung (2009) and Tanaka, Camerer and Nguyen (2010). In principal respondents (the household head) are confronted with an array of paired lotteries, A and B, of which one option has to be chosen at the same time rejecting the other one. The sMPL design is a variant of the MPL standard approach and enforces monotonic switching, i.e. respondents are not allowed to switch back and forth within one series. In the end one row is randomly selected to be played with real money that encourages truthful revelation of preferences (Andersen et al. 2006). In the following the two experiments are explained in more detail.

\section{Experiment on risk preferences}

The risk game was conceptualized in three series of paired lotteries. In each series, the respondent had the choice between two options, i.e. option A and option B, whereby each option is a lottery out of 10 colored chips with different rewards to be obtained. The respondent made his choice based on single picture cards illustrating each lottery pair. Using this illustration procedure we were confident to circumvent the weakness of MPL, i.e. the frame encouraging respondents to choose the middle row of tables (Harrison and Rutström 2008).

In total there were 35 choices to make. All scenarios are illustrated in table 1 . The difference in expected pay-offs of option A relative to option B is shown in the right column.

In series 1 , probabilities were fixed in all 14 rows and only the high pay-off in option B incrementally increased between 300 CFA and 15000 CFA.

In series 2 there were different pay-offs and probabilities as compared to series 1 , but the same pattern. Option B started immediately with a higher expected pay-off than in 
option A in row 15. In both series, a person, who is rather risk-averse, would choose Option A longer.

The third series involved both gains and losses. Probabilities were fixed at 50:50 for all rows. In option A the positive pay-off decreased, while the negative pay-off increased from row to row. In option B the positive pay-off was constantly high, and the negative pay-off decreased row by row. Accordingly, a person, who was rather loss-averse, would choose option A longer.

After the completion of all 35 choices, the respondent was asked to blindly draw one card out of 35 numbered cards in a bag. The card drawn determined the row of choice and the respective 10 colored chip lottery was then played for real money. The largest reward of 50000 CFA (about 100 US\$) was equivalent to two weeks average income of a cattle dependent household in the study area. The maximum amount that could have been lost by the respondent was 1000 CFA (about 2 US\$), which was the amount the respondent had been paid when he agreed to participate in the research.

By using the switching points in the first two series the parameter for risk aversion and probability weight can be determined. The switching points in series three help to estimate farmer's degree of loss aversion.

\section{Experiment on time preferences}

The time preference experiment was conceptualized in 15 series of five choices between two options, i.e. a smaller reward delivered immediately (Option A) and a larger reward delivered at a specified time in the future (Option B). The experiment is illustrated in table 2 . 
There were $5 \times 3$ series, where the same range of five immediate rewards was contrasted with a constant delayed reward at three different points of time in the future. Every fourth series the amount of the five immediate rewards $\left(x_{t}\right)$ and the delayed reward $\left(x_{t+\tau}\right)$ changed, but the ratio between the two was always the same, i.e. $x_{t}=\frac{x_{t+\tau} * v}{6}$, where $v=1, \ldots, 5$ is the number of row within each series. The future reward varied between $1500 \mathrm{CFA}$ and $15000 \mathrm{CFA}$ and the delay varied between three days and three months. The maximum delay of three months corresponds to treatment decisions in managing the disease. Within each series the respondent had to decide row by row which option he preferred. Again monotonic switching was enforced.

After the completion of all 75 choices, the respondent was asked to blindly draw one card out of 75 numbered cards in a sack. The card drawn determined the row and the participant gained the reward at the respective time according to his choices made. As suggested by Cardenas and Carpenter (2008), a trusted agent, well-known and commonly accepted for this duty, had been assigned to keep the money until delivery.

In the household surveys detailed economic data at farm level about input costs, output quantities and prices were collected in 2003/2004 by Affognon (2007), in 2007 by Liebenehm, Affognon and Waibel (2011) and again in 2011 by Liebenehm and Waibel (2011). In total there are 98 observations over three time periods from the same smallholder cattle farmers, 71 farmers from the circle around Sikasso in southeastern Mali and 27 farmers from the province of Kénédougou in south-western Burkina Faso. 
The data is incorporated into the estimation approach that is introduced in the next section.

\section{Methodology}

In our approach we aim to simultaneously estimate the parameters of the discounted utility model and their interrelation with farmers' socio-economic characteristics. We follow the suggestion of Harrison and Rutström (2008) and estimate the present value of future utility streams. Hence, any assumptions about the concavity of preferences as has been done in many studies (Frederick, Loewenstein, and O’Donoghue 2002) can be omitted.

In principal, the idea is to combine the estimation of risk and time preferences in one approach, by incorporating the utility function into the discounting model.

Let $U_{i}^{A ; j}$ be the utility of respondent $i$ from option $\mathrm{A}$ in scenario $j$ from the risk and the time experiment. The utility value is only known by the respondent $i$ and cannot be observed by the researcher. However, the researcher can observe the respondent's characteristics $X_{i}$ and knows all information on scenario $j$, denoted by $Z^{j}$, including prizes and probabilities in option A and B.

Further, under prospect theory, a respondent's utility from option A can be defined as:

$$
U_{i}^{A ; j}=P T_{i}^{A ; j}\left(X_{i} ; Z^{j}\right)+\varepsilon_{i}^{A ; j},
$$


where $P T_{i}^{A ; j}$ describes the utility under prospect theory and $\varepsilon_{i}^{A ; j}$ is the error term, normally and independent and identically distributed. A respondent's utility from option B in the risk experiment can be defined accordingly:

$$
U_{i}^{B ; j}=P T_{i}^{B ; j}\left(X_{i} ; Z^{j}\right)+\varepsilon_{i}^{B ; j} .
$$

Since option B in the time experiment involves monetary rewards obtained in the future, the discounting function $D_{i}$ needs to be incorporated into equation (7), which is a function of $t$ (the delay in days) and individual characteristics $X_{i}$ :

$$
U_{i}^{B ; j}=D_{i}\left(t ; X_{i}\right) P T_{i}^{B ; j}\left(X_{i} ; Z^{j}\right)+\varepsilon_{i}^{B ; j} .
$$

Hence, the present value of utility streams under both options $\mathrm{A}$ and $\mathrm{B}$ can be obtained by the means of $U_{i}^{A ; j}$ and $U_{i}^{B ; j}$, respectively.

The utility for each lottery pair in scenario $j$ can be expressed by the latent index $\nabla U_{i}^{j}$

$$
\nabla U_{i}^{j}=\frac{\left(U_{i}^{B ; j}-U_{i}^{A: j}\right)}{\mu},
$$

where $\mu$ is a noise parameter specifying a stochastic error made by the decision maker when evaluating the available choices (Wilcox 2008). Such a specification is appropriate, because experiments on time preferences in particular are very noisy (Benhabib, Bisin, and Schotter 2010).

The latent index $\nabla U_{i}^{j}$ is then linked to the observed binary choices made by the respondent in the experiments using a standard cumulative distribution function $\Phi\left(\nabla U_{i}^{j}\right)$. Any argument in equation (9) is transformed into a number between zero and one. Hence, the probability of choosing option B over A in scenario $j$ is:

$$
\operatorname{Pr}(B)=\Phi\left(\nabla U_{i}^{j}\right) .
$$


A respondent's conditional log likelihood of choosing option B depends on the utility function parameters under prospect theory $(\alpha, \sigma$ and $\lambda)$, the discount function parameters ( $\beta$ and $\delta$ ) and in total 110 observed binary choices in the risk ( 35 choices) and time experiment (75 choices). These choices are captured by $y_{i}^{j}$, which equals one if individual $i$ chooses option $\mathrm{B}$ in scenario $j$ and zero otherwise. Hence, the individual log likelihood function can be expressed as:

(11) $\ln L_{i}\left(\alpha, \sigma, \lambda ; \beta, \delta ; \mu ; X_{i} ; Z^{j} ; y_{i}^{j}\right)=\sum_{j=1}^{110}\left\{\left[\ln \Phi\left(\nabla U_{i}^{j}\right) \mid y_{i}^{j}=1\right]+\left[\ln \Phi\left(\nabla U_{i}^{j}\right) \mid y_{i}^{j}=0\right]\right\}$.

Assuming that all error terms are uncorrelated and independent and identically distributed the joint likelihood for all individuals is then:

$$
L\left(\alpha, \sigma, \lambda ; \beta, \delta ; \mu ; X_{i}\right)=\sum_{i=1}^{N} \ln L_{i}\left(\alpha, \sigma, \lambda ; \beta, \delta ; \mu ; X_{i} ; Z^{j} ; y_{i}^{j}\right)
$$

Finally, the maximum-likelihood estimation for the parameters of the utility function $(\alpha, \sigma$ and $\lambda)$ and the discounting model $(\beta$ and $\delta)$ is therefore:

$$
(\hat{\alpha}, \hat{\sigma}, \hat{\lambda} ; \hat{\beta}, \hat{\delta} ; \hat{\mu})=\arg \max L\left(\alpha, \sigma, \lambda ; \beta, \delta ; \mu ; X_{i}\right)
$$

The corresponding procedure is written in Stata to estimate the parameters and their interrelation with socio-economic characteristics $X_{i}$ using the cluster option that takes into account arbitrary intra-group correlation (Harrison 2008).

The vector $X_{i}$ comprises information on farmers' socio-economic characteristics observed over three periods of time. In particular there is information on a farmer's individual characteristics (such as age, education and experience in keeping cattle), 
household characteristics (such as household size, dependency ratio, number of children going to school and net revenue from selling bovine outputs off-farm like traction, milk and manure) and information about the exposure to the livestock disease (such as perception of AAT and its resistance to trypanocides, and expenditure on drugs). Using lag operators we can investigate if changes in $X_{i}$ over time are interrelated with pastoralists' risk and time preferences elicited at 2011. The results are presented in the next section.

\section{Results}

We split the results into two parts. First, we investigate the descriptive statistics of the socio-economic data obtained over three waves and the experimental data. This was done to identify key variables that are later used in the analysis of preferences. Second, we present the results of the structural analysis.

\section{Descriptive analysis}

Table 3 presents the socio-economic characteristics of the 98 cattle farm households observed over three years 2003/2004, 2007 and 2011.

The majority of households $(72.45 \%)$ live in south-eastern Mali. The average household head is under 60 years old, spending almost half of his lifetime keeping cattle. Also, he has spent less than 1 year in a formal school.

When comparing the average values over time, it can be seen that there are significant changes in household characteristics and in the perception of AAT prevalence and resistance. 
With respect to household characteristics, households become larger over time with more children at schoolii ${ }^{\mathrm{iii}}$ and a lower dependency ratio. Over the same time, net revenue from off-farm sales of bovine outputs has steadily increased by $50 \%$ year on year.

The number of assets does not significantly change over time. On average there are about 7 means of transports such as bicycles, motorbikes or cars available. The number of cattle ranges between 16 and 20, which is below the sub-Saharan average, i.e. 38 animals ranging between 7 and 77 animals (Otte and Chilonda 2002).

The perception of disease prevalence has increased from 2003/2004 to 2011. In contrast, the perception of resistance has increased from $2003 / 2004$ to 2007 , but then strongly decreased from 2007 to 2011.

Expenditure on trypanocidal drugs varies between $84 \$$ PPP in 2003/2004 and $114 \$$ PPP in 2007. At a cost of approximately $1 \$$ per treatment (Kristjanson et al. 1999) and an average herd size of maximal 20 cattle it can be assumed that farmers treat their animals with trypanocides relative frequently over all time periods. The decrease in the perception of resistance in 2011 is not represented in the value of treatment expenditures. Therefore, in the later analysis trypanocide expenditures are used as a proxy for the prevalence of disease and resistance.

Next, we focus on the descriptive analysis of the data obtained from the risk and the time experiment. In particular we consider the switching points from option A to option B. The switching points in the first two series of the risk experiment determine 
the parameter for risk aversion and probability weighting. The switching points in series three help to measure farmer's degree of loss aversion. The switching points in the time experiment determine the parameter of present biasedness and of time preference.

Figure 1 shows the percentage of respondents by switching points in the risk experiment. There are respondents at any given switching point from $\mathrm{A}$ to $\mathrm{B}$, including the option to never switch, which suggests that the experimental instructions had been understood.

Focusing on the switching points in series one and two, the majority of respondents (about $60 \%$ ) had switched earlier rather than later to option B, trying to obtain a higher reward at a low probability. In contrast, approximately $25 \%$ never switched to option B, to obtain $500 \mathrm{CFA}$, a lower reward at 70\%, a higher, probability.

In series three the distribution of respondents by switching point is similar. About $60 \%$ of participants were more likely to switch in the beginning, taking into account the risk to lose money. About $27 \%$ of respondents never switched to option $\mathrm{B}$, which suggests that they tend to be rather loss-averse.

Figure 2 plots the cumulative probability distribution of respondents' choices made for option A and option B across different delays in days. As can be seen, option B (delayed option) is dominating option A (immediate option) in every delay. However, there is a tendency that the domination of B over A slightly decreases with an increase in delay, because the distance between A and B becomes smaller. From 
this graph, one could argue that the majority of respondents are rather patient, ready to wait for the higher reward.

Summarizing the descriptive analysis we observed that households have become larger over time with more children at school and with a lower dependency ratio. Their net revenue from off-farm sales of cattle outputs also steadily increased, although their animals are strongly exposed to AAT and drug resistance. It is also shown that the majority of respondents in the experiments are not afraid to take risks in gains and losses and are ready to wait for the higher reward ${ }^{\mathrm{iv}}$. In the next step we are going to analyze the relationship between the socio-economic characteristics and elicited preferences.

\section{Structural analysis}

In the structural analysis the parameters of the discounted utility function are estimated simultaneously by means of a maximum likelihood program written in Stata. In the first step we assume that respondents are homogenous in their preferences and exclude individual covariates. In the second step we include individual covariates in order to analyze the interrelation between elicited preferences and socio-economic characteristics. In both analyses, each farmer forms a cluster, in which all 110 binary choices from both experiments are observed. In total, 10780 observations are obtained, which corresponds to 98 clusters.

Table 4 presents the maximum likelihood estimates excluding individual covariates. The estimate of the probability weighting parameter is 0.313 and it is significantly different from 1 in the one sided t-test. From this estimate it can be concluded that the 
probability weighting function is inverted s-shaped and respondents seem to overweight small probabilities and underweight large probabilities.

With respect to risk aversion, the estimated exponent of the value function is 0.559 . Further, the estimated coefficient of the loss aversion parameter is 1.085 and the onesided test shows that the coefficient is not significantly different from 1 . Hence, there is little evidence that respondents are averse to losses.

The estimate of the time preference parameter $(\delta)$, i.e. 0.003 , and the estimate of the present biasedness $(\beta)$, i.e. 0.788 , suggest that respondents are rather patient and associate a relatively low variable cost to utility streams obtained in the future.

The estimate of the noise parameter is not significant but relatively large, which is likely due to the experiment on time preferences that are usually very noisy (Benhabib, Bisin, and Schotter 2010).

In comparison to similar studies in Asian developing countries it can be noticed that the estimates on the probability weight, on the loss aversion parameter and on impatience are much smaller in this study. In particular the relatively low value of $\lambda$ indicates that the small-holder cattle farmers in West Africa are less loss-averse than Vietnamese villagers (Tanaka, Camerer, and Nguyen 2010), Vietnamese fishermen (Nguyen and Leung 2010) or Chinese farmers (Liu 2008). Also the estimate on the subjective discount rate and the estimate on present biasedness imply that the West African pastoralists are more patient and less present biased than the estimates of quasi-hyperbolic specification in the study of Tanaka, Camerer, and Nguyen (2010) suggest. 
In contrast, the estimate of the curvature parameter $\sigma$ is similar to results found in other studies. For example Tanaka, Camerer and Nguyen (2010) found an average value of 0.59 for Vietnamese villagers in the south and a value of 0.63 for villagers from the north. Nguyen and Leung (2010) found a mean value of risk parameter of about 0.62 for livestock farmers in Vietnam.

In a second step we now establish a relationship between cattle farmers' risk and time preferences and their socio-economic characteristics and simultaneously estimate the five parameters against individual covariates observed over three time periods. Lag operators $(\Delta)$ are included in the model to capture the cumulative dynamic effect of characteristics observed in 2003/2004 and 2007 on farmers' risk and time attitudes elicited in 2011. Variables without the lag operator $(\Delta)$, such as country of origin and education, do not change over time and their values used are those observed in 2011. It is investigated how changes in household characteristics and disease exposure (as measured by expenditures for trypanocidal drugs) over time correlate with cattle farmers' risk and time preferences ${ }^{\mathrm{v}}$. The joint model estimates of risk ${ }^{\mathrm{vi}}$ and time preferences are separately presented in table $5 \mathrm{a}$ and $5 \mathrm{~b}$, respectively.

The analysis shows that cattle farmers from Burkina Faso tend to overweight probabilities and are more averse towards risks in gains and losses than cattle farmers from Mali.

Regarding farmers' individual characteristics, like age and education, it can be found that older farmers are significantly more risk and loss-averse, which is in accordance with many recent studies in the developing world, e.g. Tanaka, Camerer and Nguyen 
(2010), Nguyen \& Leung (2009) or Yesuf \& Bluffstone (2009). In contrast to those studies we find a negative impact of education on risk aversion that indicates that those farmers with higher levels of education are less averse to risks.

With respect to household characteristics the household size and the number of children that are enrolled in school significantly affect risk aversion. The cumulative dynamic effect of an increase in household size on risk and loss aversion is positive, while the cumulative dynamic effect of an increase in number of children at school is negative. That means that farmers living in larger households are less likely to take risk both in gains and losses. However, when more of their children are attending school they appear more likely to take risks.

Assets such as the number of cattle have a negative impact on farmers' risk aversion, but a positive impact on farmers' loss aversion. In other words, farmers possessing more cattle are less risk-averse but more loss-averse. This is in line with the study of Yesuf and Bluffstone (2009), which finds that number of oxen reduces the riskaversion of rural Ethiopian farmers.

The dynamic effect of an increase in net revenue obtained from off-farm sales of cattle products is negative both for risk and loss aversion. That means that those farmers with higher net revenue are more ready to take risk in gains and losses. This result is consistent with the literature (Yesuf and Bluffstone 2009; Tanaka, Camerer, and Nguyen 2010).

Finally, the exposure to cattle disease (AAT) and resistance, as proxied by expenditures for trypanocidal drugs, is positive on risk aversion, but not significant. 
The more prevalent the disease is (and the higher the expenditures), the more likely the farmer tends to avoid risk.

Table $5 \mathrm{~b}$ presents the second part of the estimates of time preference parameters in the discounted utility model. It was found that the number of children at school, education of the household head and perceived disease pressure, as proxied by expenditures for trypanocidal drugs, lower farmers' discount rates. In other words, those farmers' with higher levels of education and who send their children to school are found to be more patient. Moreover, an increase in AAT prevalence and resistance makes cattle farmers more patient.

However, farmers living in larger households and obtaining more cattle and higher net revenue from off-farm sales are found to be less patient. This result is quiet surprising, because it is not consistent with the general hypothesis that a wealthier farmer is more patient than a poorer farmer (Fisher 1930; Pender 1996; Nielsen 2001; Harrison, Lau, and Williams 2002; Anderson et al. 2004).

The only variables that show a significant influence on present biasedness are the number of household members and expenditures on drug treatment. The cumulative dynamic effect of an increase in household size is positive on farmers' present bias, which means that farmers living in larger households are more present biased. A perceived increase in the prevalence of AAT and drug resistance, as proxied by drug expenditures, is found to decrease present biasedness. 


\section{Summary and conclusions}

We developed a discounted utility model, where we define a prospect theory-based utility function and a quasi-hyperbolic discounting function in order to estimate the present value of future utility streams. We estimated two models that capture the dynamic decision making behavior of cattle farmers in relation to AAT management. The first model simultaneously provides parameters of risk and time preference and the second model explains these parameters against the background of socioeconomic characteristics of West African cattle farmers.

Results of the first model show that the risk aversion coefficient is similar to those found in Asian studies. However, we find lower values of loss aversion and a higher degree of patience for our West African small-holder pastoralists as compared to the Asian farmers/fishermen (see e.g. Tanaka, Camerer, and Nguyen 2010, Nguyen and Leung 2010, Liu 2008).

From the point of view of disease management these results suggest that the "West African cattle farmer" adopts strategies which include the possibility of treatment failure, but does not show any aversion against the more expensive preventive strategies, where benefits are realized later.

From the second model we find that households who send more of their children to school are willing to take risks and give a higher weight to future benefits. Farmers, who own more cattle, are less risk-averse. This is in line with Yesuf and Bluffstone (2009), who find that the number of oxen owned reduces the risk-aversion of rural Ethiopian farmer. 
Regarding time preferences, larger cattle herds have a significant negative effect on patience. We can show that the increase in net revenues from selling milk, manure and draft power decreases risk aversion. This result is consistent with findings of Tanaka, Camerer and Nguyen (2010) and Yesuf \& Bluffstone (2009). However, the increase in net revenue influences patience negatively. Here we contradict to the existing literatures from Asia (e.g. Pender 1996; Anderson et al. 2004). While there could be several reasons for cultural differences in such behavior, further research, which is beyond the scope of this study, is needed.

Another important variable hypothesized to explain risk and time preference is farmers' perception of disease pressure. For time preference we find a significant positive effect, while the variable was not significant for the risk coefficient. This seems plausible, because farmers exposed to high disease pressure tend to have more experience with disease management and may therefore adopt preventive measures ${ }^{\mathrm{vii}}$.

The results provide a possible explanation for the lack of adoption of sustainable treatment measures. Wealthier farmers, who are less risk averse and less patient, will prefer the cheaper curative measures. This contradicts expert recommendations, who consider curative treatments in most cases as inefficient (Clausen et al. 2010). Hence, extension messages have to be formulated in such a way that they address the socioeconomic characteristics of the farmers. To further verify these results, in the next step of the analysis, we will make use of the results of our dynamic experiment. In this experiment, which included three stages to stimulate a learning process among the respondents, pay-off distributions depending on the chosen treatment had to be 
evaluated. We can then show the willingness to pay for curative and preventive treatments.

Following the request of Dercon in his paper "Fate and Fear: Risk and Its Consequences in Africa" (2008), our study contributes to the badly needed empirical works on risk and time preferences in Africa. In this sense our research presents a first albeit an important step towards a better understanding of decision making among farmers living in ecological sensitive areas, where people's livelihood are increasingly threatened. 


\section{References}

Affognon, H. 2007. "Economic Analysis of Trypanocide Use in Villages under Risk of Drug Resistance in West Africa." PhD dissertation, Leibniz University of Hannover.

Agyemang, K., R.H. Dwinger, A.S. Grieve, and M.L. Bah. 1991. "Milk Production Characteristics and Productivity of N'Dama Cattle Kept Under Village Management in The Gambia.” Journal of Dairy Science 74 (5): 1599-1608.

Andersen, S., G.W. Harrison, M.I. Lau, and E.E. Rutstrom. 2008. "Eliciting Risk and Time Preferences." Econometrica 76 (3): 583-618.

Andersen, S., G.W. Harrison, M.I. Lau, and E.E. Rutström. 2006. "Elicitation using Multiple Price List Formats.” Experimental Economics 9 (4): 383-405.

Anderson, C. L., M. Dietz, A. Gordon, and M. Klawitter. 2004. "Discount Rates in Vietnam." Economic Development and Cultural Change 52 (4): 873-887.

Benhabib, J., A. Bisin, and A. Schotter. 2010. "Present-Bias, Quasi-Hyperbolic Discounting, and Fixed Costs." Games and Economic Behavior 69 (2): 205 223.

Binswanger, H.P. 1980. “Attitudes Toward Risk: Experimental Measurement in Rural India." American Journal of Agricultural Economics 62 (3): 395-407.

—. 1981. “Attitudes Toward Risk: Theoretical Implications of an Experiment in Rural India.” The Economic Journal 91: 867-890.

Brick, K., M. Visser, and J. Burns. 2012. "Risk Aversion: Experimental Evidence from South African Fishing Communities.” American Journal of Agricultural Economics 94 (1): 133-152. 
Cardenas, J.C., and J. Carpenter. 2008. "Behavioural Development Economics: Lessons from Field Labs in the Developing World." Journal of Development Studies 44: 311-338.

Clausen, P.-H., B. Bauer, K.-H. Zessin, O. Diall, Z. Bocoum, I. Sidibe, H. Affognon, H. Waibel, D. Grace, and T. Randolph. 2010. "Preventing and Containing Trypanocide Resistance in the Cotton Zone of West Africa." Transboundary and Emerging Diseases 57 (1-2): 28-32.

Dercon, S. 2008. "Fate and Fear: Risk and Its Consequences in Africa." Journal of African Economics 17 (2): ii97-ii127.

Fafchamps, M., C. Udry, and K. Czukas. 1998. "Drought and Saving in West Africa: Are Livestock a Buffer Stock.” Journal of Development Economics: 273--306.

Fisher, I. 1930. The Theory of Interest. New York: The Macmillian Co.

Frederick, S., G. Loewenstein, and T. O’Donoghue. 2002. “Time Discounting and Time Preference: A Critical Review.” Journal of Economic Literature 40 (2): $351-401$.

Grace, D., T.F. Randolph, H. Affognon, D. Dramane, O. Diall, and P. Clausen. 2009. “Characterisation and Validation of Farmers' Knowledge and Practice of Cattle Trypanosomosis Management in the Cotton Zone of West Africa." Acta Tropica 111 (2): 137-143.

Green, L., J. Myerson, and E. McFadden. 1997. "Rate of Temporal Discounting Decreases with Amount of Reward." Memory \& Cognition 25 (5): 715-723.

Hardeweg, B., L. Menkhoff, and H. Waibel. Forthcoming. "Experimentally Validated Survey Evidence on Individual Risk Attitudes in Rural Thailand.” Economic Development and Cultural Change, in press. 
Harrison, G, and E. Rutström. 2008. "Expected Utility Theory and Prospect Theory: One Wedding and a Decent Funeral.” Experimental Economics 12 (2): 133158.

Harrison, G. 2008. "Maximum Likelihood Estimation of Utility Functions Using Stata." Working paper, Department of Economics, College of Business Administration, University of Central Florida.

Harrison, G. W., and E. Rutström. 2008. "Risk Aversion in the Laboratory." In J. C. Cox, and G. W. Harrison, ed., Risk Aversion in Experiments. Bingley, UK: Emerald Group Publishing Limited, pp. 41-196.

Harrison, G. W., M.I. Lau, and M.B. Williams. 2002. "Estimating Individual Discount Rates in Denmark: A Field Experiment." American Economic Review 92 (5): 1606-1617.

Ida, T., and R. Goto. 2009. "Interdependency Among Addictive Behaviours and Time/Risk Preferences: Discrete Choice Model Analysis of Smoking, Drinking, and Gambling.” Journal of Economic Psychology 30 (4): 608-621.

Kahneman, D., and A. Tversky. 1979. "Prospect Theory: An Analysis of Decision under Risk." Econometrica 47 (2): 263-291.

Kristjanson, P.M., B.M. Swallow, G.J. Rowlands, R.L. Kruska, and P.N. de Leeuw. 1999. "Measuring the Costs of African Animal Trypanosomosis, the Potential Benefits of Control and Returns to Research.” Agricultural Systems 59 (1): 7998.

Laibson, D. 1997. “Golden Eggs and Hyperbolic Discounting.” Quarterly Journal of Economics 112 (2): 443-477. 
Liebenehm, S., H. Affognon, and H. Waibel. 2011. "Collective Livestock Research for Sustainable Disease Management in Maliand Burkina Faso.” International Journal of Agricultural Sustainability 9 (1): 212-221.

Liebenehm, S., and H. Waibel. 2011. "Attitudes towards Risk and Time among Small-Scale Farmers in West Africa." Paper presented at PEGNet Conference, GIGA German Institute of Global and Area Studies, Hamburg, Germany, 0709 September.

Liu, E.M. 2008. "Time to Change What to Sow: Risk Preferences and Technology Adoption Decisions of Cotton Farmers in China.” Working paper, Department of Economics, Princton University.

Loewenstein, G., and D. Prelec. 1992. “Anomalies in Intertemporal Choice: Evidence and an Interpretation.” Quarterly Journal of Economics 107 (2): 573-597.

Mungube, E. 2010. Management of Trypanocidal Drug Resistance in Cattle in Identified Chemo-Resistance Hot Spots in the Administrative District of Sikasso, South-East Mali. Berlin, Germany: mensch und buch verlag (mbv).

Nguyen, Q., and P. Leung. 2009. "Do Fishermen Have Different Attitudes Toward Risk? An Application of Prospect Theory to the Study of Vietnamese Fishermen." Journal of Agricultural and Resource Economics 34 (3): 518538.

—. 2010. "How Nurture Can Shape Preferences: An Experimental Study on Risk Preferences of Vietnamese Fishers." Environment and Development Economics 15 (05): 609-631.

Nielsen, U. 2001. "Poverty and Attitudes towards Time and Risk-Experimental Evidence from Madagascar." Working Paper. Royal Veterinary and Agricultural University of Denmark. 
O’Donoghue, T., and M. Rabin. 1999. “Doing It Now or Later.” American Economic Review 89 (1): 103-124.

Otte, M.J., and P. Chilonda. 2002. Cattle and Small Ruminant Production Systems in Sub-Saharan Africa - A systematic review. Rome, Italy: FAO.

Pender, J.L. 1996. "Discount Rates and Credit Markets: Theory and Evidence from Rural India." Journal of Development Economics 50 (2): 257-296.

Prelec, D. 1998. "The Probability Weighting Function.” Econometrica 66 (3): 497528.

Tanaka, T., C. F. Camerer, and Q. Nguyen. 2010. Risk and Time Preferences: Linking Experimental and Household Survey Data from Vietnam. American Economic Review, 100(1): 557-571.

Thaler, R.H., and H.M. Shefrin. 1981. "An Economic Theory of Self-Control.” Journal of Political Economy 89 (2): 392-406.

Tversky, A., and D. Kahneman. 1992. “Advances in Prospect Theory: Cumulative Representation of Uncertainty." Journal of Risk and Uncertainty 5 (4): $297-$ 323.

Wik, M., T.A. Kebede, O. Bergland, and S.T. Holden. 2004. "On the Measurement of Risk Aversion from Experimental Data.” Applied Economics 36 (21): 24432451

Wilcox, N.T. 2008. "Stochastic Models for Binary Discrete Choice under Risk: A Critical Primer and Econometric Comparison." Research in Experimental Economics 12: 197-292.

Yesuf, M., and R. A. Bluffstone. 2009. "Poverty, Risk Aversion, and Path Dependence in Low-Income Countries: Experimental Evidence from Ethiopia." American Journal of Agricultural Economics 91 (4): 1022-1037. 
Table 1. Design of Risk Experiment

\begin{tabular}{|c|c|c|c|c|c|c|}
\hline \multirow[t]{3}{*}{ Series } & \multirow[t]{3}{*}{ Rows } & \multicolumn{2}{|c|}{ Option A } & \multicolumn{2}{|c|}{ Option B } & $\begin{array}{l}\text { Difference } \\
\text { in } \\
\text { expected } \\
\text { pay-off }\end{array}$ \\
\hline & & Prob: & & Proba & & \\
\hline & & $30 \%$ & $70 \%$ & $10 \%$ & $90 \%$ & \\
\hline \multirow{7}{*}{1} & 1 & 2000 & 500 & 3000 & 250 & 425 \\
\hline & $\ldots$ & & & & & \\
\hline & 7 & 2000 & 500 & 7000 & 250 & 25 \\
\hline & 14 & 2000 & 500 & 50000 & 250 & -4275 \\
\hline & & Prob: & & Proba & & \\
\hline & & $90 \%$ & $10 \%$ & $70 \%$ & $30 \%$ & \\
\hline & 15 & 2000 & 1500 & 2500 & 250 & -100 \\
\hline \multirow[t]{7}{*}{2} & $\ldots$ & & & & & \\
\hline & 21 & 2000 & 1500 & 3200 & 250 & -660 \\
\hline & 28 & 2000 & 1500 & 6500 & 250 & -3300 \\
\hline & & Prob & & Proba & & \\
\hline & & $50 \%$ & $50 \%$ & $50 \%$ & $50 \%$ & \\
\hline & 29 & 1200 & -200 & 1500 & -1000 & 250 \\
\hline & 30 & 200 & -200 & 1500 & -1000 & -250 \\
\hline \multirow[t]{5}{*}{3} & 31 & 50 & -200 & 1500 & -1000 & -325 \\
\hline & 32 & 50 & -200 & 1500 & -800 & -425 \\
\hline & 33 & 50 & -400 & 1500 & -800 & -525 \\
\hline & 34 & 50 & -400 & 1500 & -700 & -575 \\
\hline & 35 & 50 & -400 & 1500 & -500 & -675 \\
\hline
\end{tabular}


Table 2. Design of Time Experiment

\begin{tabular}{|c|c|c|c|c|c|c|c|c|c|}
\hline Series & Rows & $\begin{array}{l}\text { Option } \\
\text { A }\end{array}$ & $\begin{array}{l}\text { Option } \\
\text { B }\end{array}$ & Series & Rows & $\begin{array}{l}\text { Option } \\
\text { B }\end{array}$ & Series & Rows & $\begin{array}{l}\text { Option } \\
\text { B }\end{array}$ \\
\hline \multirow{5}{*}{1} & 1 & 250 & \multirow{5}{*}{$\begin{array}{l}1500 \\
\text { in } 1 \\
\text { week }\end{array}$} & \multirow{5}{*}{2} & 6 & \multirow{5}{*}{$\begin{array}{l}1500 \\
\text { in } 1 \\
\text { month }\end{array}$} & \multirow{5}{*}{3} & 11 & \multirow{5}{*}{$\begin{array}{l}1500 \\
\text { in } 3 \\
\text { months }\end{array}$} \\
\hline & 2 & 500 & & & 7 & & & 12 & \\
\hline & 3 & 750 & & & 8 & & & 13 & \\
\hline & 4 & 1000 & & & 9 & & & 14 & \\
\hline & 5 & 1250 & & & 10 & & & 15 & \\
\hline \multirow{5}{*}{4} & 16 & 1000 & & \multirow{5}{*}{5} & 21 & \multirow{5}{*}{$\begin{array}{l}6000 \\
\text { in } 1 \\
\text { month }\end{array}$} & \multirow{5}{*}{6} & 26 & \multirow{5}{*}{$\begin{array}{l}6000 \\
\text { in } 3 \\
\text { months }\end{array}$} \\
\hline & 17 & 2000 & 6000 & & 22 & & & 27 & \\
\hline & 18 & 3000 & in 1 & & 23 & & & 28 & \\
\hline & 19 & 4000 & week & & 24 & & & 29 & \\
\hline & 20 & 5000 & & & 25 & & & 30 & \\
\hline \multirow{5}{*}{7} & 31 & 2500 & & \multirow{5}{*}{8} & 36 & \multirow{5}{*}{$\begin{array}{l}15000 \\
\text { in } 1 \\
\text { months }\end{array}$} & \multirow{5}{*}{9} & 41 & \multirow{5}{*}{$\begin{array}{l}15000 \\
\text { in } 3 \\
\text { months }\end{array}$} \\
\hline & 32 & 5000 & 15000 & & 37 & & & 42 & \\
\hline & 33 & 7500 & in 1 & & 38 & & & 43 & \\
\hline & 34 & 10000 & week & & 39 & & & 44 & \\
\hline & 35 & 12500 & & & 40 & & & 45 & \\
\hline \multirow{5}{*}{10} & 46 & 2000 & & \multirow{5}{*}{11} & 51 & \multirow{5}{*}{$\begin{array}{l}12000 \\
\text { in } 2 \\
\text { weeks }\end{array}$} & \multirow{5}{*}{12} & 56 & \multirow{5}{*}{$\begin{array}{l}12000 \\
\text { in } 2 \\
\text { months }\end{array}$} \\
\hline & 47 & 4000 & 12000 & & 52 & & & 57 & \\
\hline & 48 & 6000 & in 3 & & 53 & & & 58 & \\
\hline & 49 & 8000 & days & & 54 & & & 59 & \\
\hline & 50 & 10000 & & & 55 & & & 60 & \\
\hline \multirow{5}{*}{13} & 61 & 500 & & \multirow{5}{*}{14} & 66 & \multirow{5}{*}{$\begin{array}{l}3000 \\
\text { in } 2 \\
\text { weeks }\end{array}$} & \multirow{5}{*}{15} & 71 & \multirow{5}{*}{$\begin{array}{l}3000 \\
\text { in } 2 \\
\text { month }\end{array}$} \\
\hline & 62 & 1000 & 3000 & & 67 & & & 72 & \\
\hline & 63 & 1500 & in 3 & & 68 & & & 73 & \\
\hline & 64 & 2000 & days & & 69 & & & 74 & \\
\hline & 65 & 2500 & & & 70 & & & 75 & \\
\hline
\end{tabular}


Table 3. Descriptive Statistics of Households over Time

\begin{tabular}{|c|c|c|c|c|}
\hline \multirow[b]{2}{*}{ Variable } & \multicolumn{3}{|l|}{ Mean } & \multirow[b]{2}{*}{ F-test } \\
\hline & $\begin{array}{l}2003 / 2004 \\
\text { (a) }\end{array}$ & $\begin{array}{l}2007 \\
\text { (b) }\end{array}$ & $\begin{array}{l}2011 \\
\text { (c) }\end{array}$ & \\
\hline Country $($ Burkina Faso $=1)$ & 27.55 & 27.55 & 27.55 & 0 \\
\hline Age of $\mathrm{HH}$ Head & 53.75 & $58.3^{\mathrm{a}}$ & $59.73^{a b}$ & $4.84 * * *$ \\
\hline $\begin{array}{l}\text { Formal education of } \mathrm{HH} \text { Head } \\
\text { (years) }\end{array}$ & 0.8 & 0.69 & 0.77 & 0.06 \\
\hline $\begin{array}{l}\text { Experience of HH Head } \\
\text { in cattle keeping (years) }\end{array}$ & na & na & 25.7 & $\mathrm{Na}$ \\
\hline Household size & 24.33 & 19.98 & $27.06^{b}$ & $4.8^{* * *}$ \\
\hline Dependency ratio & 0.92 & $0.43^{\mathrm{a}}$ & $0.44^{\mathrm{ab}}$ & $44.48 * * *$ \\
\hline Children at school & 3.6 & $5.44^{\mathrm{a}}$ & $6.61^{\mathrm{ab}}$ & $10.81 * * *$ \\
\hline Number of means of transport & na & 6.77 & $7.92^{b}$ & $3.63 *$ \\
\hline Number of cattle & 17.12 & 16.06 & 20.6 & 1.07 \\
\hline $\begin{array}{l}\text { Net revenue from off-farm sales } \\
\text { of bovine products }(\$ P P P)\end{array}$ & 1743.9 & $2236.52^{a}$ & $3192.06^{\mathrm{ab}}$ & $69.88 * * *$ \\
\hline Disease prevalence $(\%)$ & 50 & 62.25 & $87.76^{\mathrm{ab}}$ & $18.22 * * *$ \\
\hline Resistance prevalence (\%) & 62.25 & $76.53^{\mathrm{a}}$ & $26.04^{\mathrm{ab}}$ & $32.04 * * *$ \\
\hline $\begin{array}{l}\text { Expenditures for drug } \\
\text { treatment }(\$ \mathrm{PPP})\end{array}$ & 83.87 & 114.37 & 101.11 & 0.99 \\
\hline $\mathrm{N}$ & 98 & 98 & 98 & \\
\hline
\end{tabular}

Note: Single, double, and triple asterisks $(*, * *, * * *)$ denote $\mathrm{p}<0.10,0.05$, and 0.01 , respectively. 


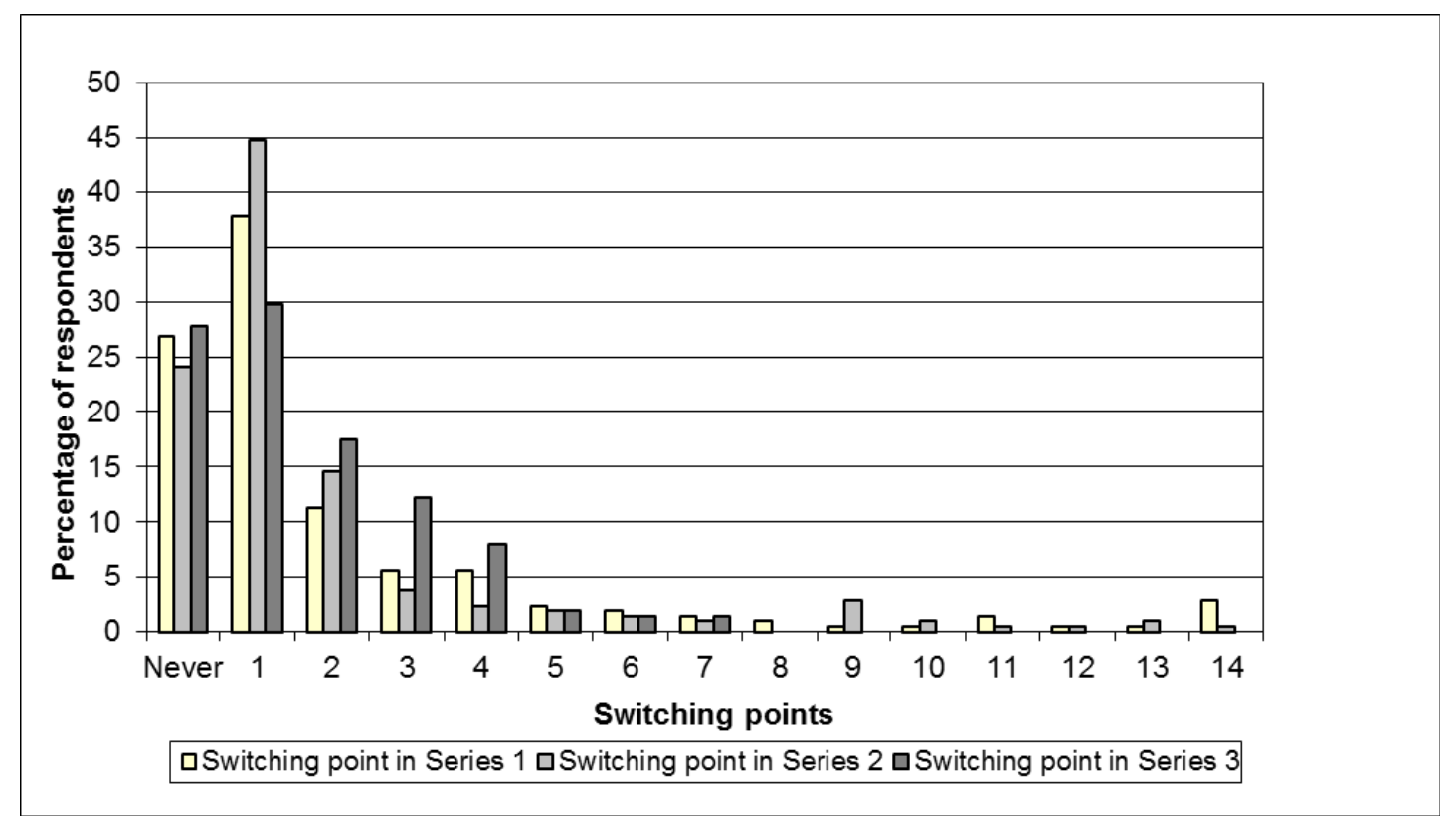

Figure 1. Percentage of Respondents by Switching Point in Risk Experiment 


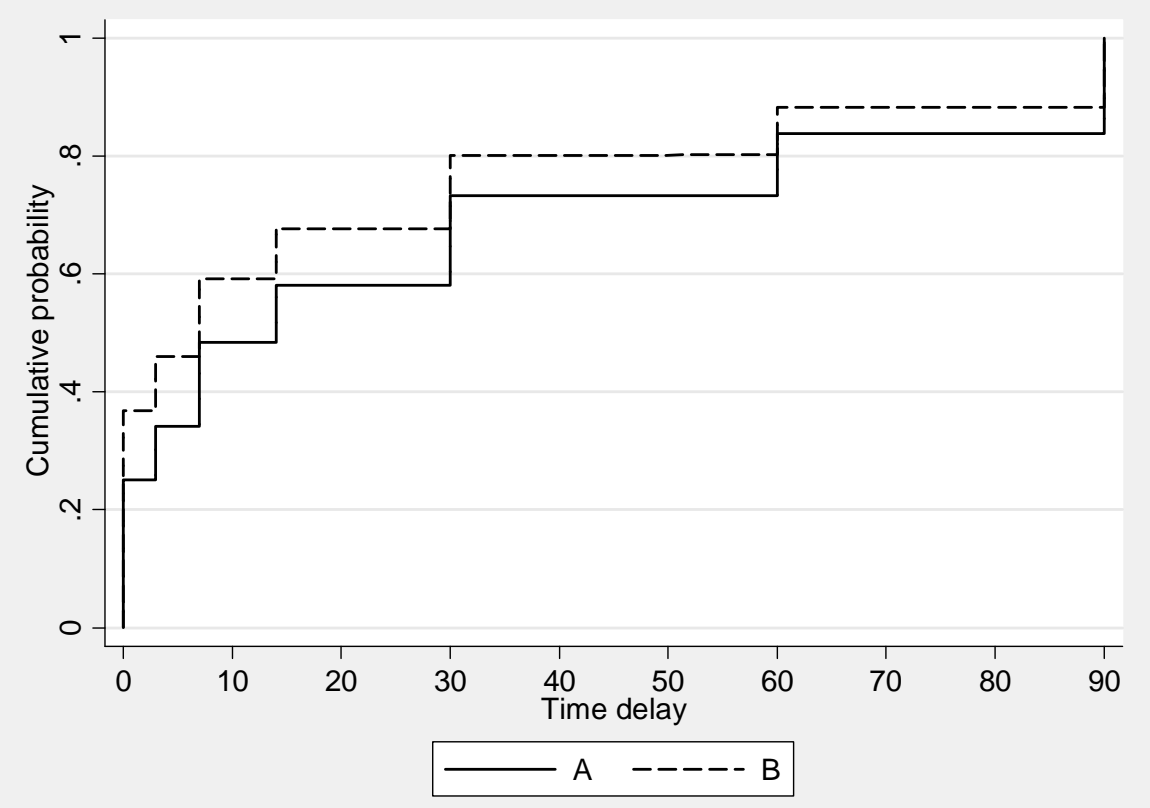

Figure 2. Cumulative Probability Distribution of Choices across Delay in Time Experiment 
Table 4. Model Estimates of Parameters without Individual Characteristics

\begin{tabular}{|c|c|c|c|c|c|}
\hline Parameter & Estimate & $\begin{array}{l}\text { Standard } \\
\text { error }\end{array}$ & p-value & $\begin{array}{l}\text { Lower } 95 \% \\
\text { confidence } \\
\text { interval }\end{array}$ & $\begin{array}{l}\text { Upper } \\
95 \% \\
\text { confidence } \\
\text { interval }\end{array}$ \\
\hline $\begin{array}{l}\text { Probability weight } \\
(\alpha)\end{array}$ & 0.313 & 0.066 & 0.000 & 0.185 & 0.442 \\
\hline Risk aversion $(\sigma)$ & 0.559 & 0.080 & 0.000 & 0.402 & 0.717 \\
\hline Loss aversion $(\lambda)$ & 1.085 & 0.885 & 0.220 & -0.65 & 2.819 \\
\hline Time preference $(\delta)$ & 0.003 & 0.001 & 0.002 & 0.001 & 0.004 \\
\hline Present bias $(\beta)$ & 0.788 & 0.117 & 0.000 & 0.56 & 1.017 \\
\hline Noise $(\mu)$ & 157.277 & 132.671 & 0.236 & -102.754 & 417.308 \\
\hline \multicolumn{6}{|l|}{ Test } \\
\hline $\mathrm{H} 0: \alpha=1$ & & & 0.000 & & \\
\hline $\mathrm{H} 0: \lambda=1$ & & & 0.924 & & \\
\hline $\mathrm{H} 0: \beta=1$ & & & 0.070 & & \\
\hline $\mathrm{H} 0: \mu=1$ & & & 0.239 & & \\
\hline
\end{tabular}

Note: $\mathrm{N}=10780$ (Number of clusters $=98$ ) 
Table 5a: Model Estimates of Risk Preference Parameters with Individual

Characteristics

\section{Probability weight}

$(\alpha)$

\begin{tabular}{|c|c|c|c|}
\hline Variable & Estimate & Estimate & Estimate \\
\hline $\begin{array}{l}\text { Country (Burkina } \\
\text { Faso=1) }\end{array}$ & 2.047 & $-1.031 * * *$ & 114.104 \\
\hline$\Delta$ Age of HH Head & 0.078 & $-0.023 * * *$ & 5.106 \\
\hline Education of $\mathrm{HH}$ Head & -0.371 & $0.147 * * *$ & -20.637 \\
\hline$\Delta$ Household size & 0.058 & $-0.023 * * *$ & 2.559 \\
\hline$\Delta$ Children at school & -0.344 & $0.148 * * *$ & -21.747 \\
\hline$\Delta$ Number of cattle & -0.027 & $0.006 * * *$ & 2.719 \\
\hline $\begin{array}{l}\Delta \text { Net revenue from } \\
\text { off-farm sales of } \\
\text { bovine products ( } \$ \\
\text { PPP) }\end{array}$ & -0.001 & $0.0003 * * *$ & -0.024 \\
\hline $\begin{array}{l}\Delta \text { Expenditures for } \\
\text { drug treatment (\$ PPP) }\end{array}$ & 0.009 & -0.001 & -0.149 \\
\hline \multicolumn{4}{|c|}{$\mathrm{N}=10780($ Number of clusters $=98)$} \\
\hline Pseudo-Log Likelihood & $=-2061.4774$ & & \\
\hline
\end{tabular}

Note: Single, double, and triple asterisks $(*, * *, * * *)$ denote $\mathrm{p}<0.10,0.05$, and 0.01 , respectively

Risk aversion $(\sigma) \quad$ Loss aversion $(\lambda)$ 
Table 5b: Model Estimates of Time Preference Parameters with Individual Characteristics

\begin{tabular}{|c|c|c|}
\hline & Discount rate $(\delta)$ & Present bias $(\beta)$ \\
\hline Variable & Estimate & Estimate \\
\hline Country (Burkina Faso=1) & 0.014 & -0.286 \\
\hline$\Delta$ Age of $\mathrm{HH}$ Head & 0.0004 & 0.001 \\
\hline Education of HH Head & $-0.012 * *$ & 0.019 \\
\hline$\Delta$ Household size & $0.008 * * *$ & $-0.028 * *$ \\
\hline$\Delta$ Children at school & $-0.019 * *$ & 0.042 \\
\hline$\Delta$ Number of cattle & $0.003 * * *$ & -0.012 \\
\hline $\begin{array}{l}\Delta \text { Net revenue from off-farm } \\
\text { sales of bovine products (\$ PPP) }\end{array}$ & $0.0001 * *$ & 0.0001 \\
\hline $\begin{array}{l}\Delta \text { Expenditures for drug } \\
\text { treatment }(\$ \text { PPP) }\end{array}$ & $-0.001 * *$ & $0.003 * *$ \\
\hline \multicolumn{3}{|c|}{$\mathrm{N}=10780($ Number of clusters $=98)$} \\
\hline \multicolumn{3}{|c|}{ Pseudo-Log Likelihood $=-2061.4774$} \\
\hline
\end{tabular}


${ }^{\mathrm{i}}$ Although the risk aversion index of the Constant Relative Risk Aversion (CRRA) family cannot be equated with utility curvature under prospect theory (Wakker 2008), the terminology of "concavity" and "risk aversion" is used interchangeably in this article.

${ }^{\text {ii }}$ Having applied the general model it is found that the quasi-hyperbolic specification best fits the data.

iii It is common in the context of West African small-holder pastoralists that not all children of the household are sent to school.

iv The risk-seeking behavior of the majority of respondents had been observed in other experiments as well. For more details see Liebenehm and Waibel (2011).

${ }^{\mathrm{v}}$ The model had been controlled for heteroskedasticity and autocorrelation.

${ }^{v i}$ With respect to the interpretation of the coefficients on risk aversion, it has to be considered that a negative value of the coefficient implies that the variable has a positive impact on risk aversion.

${ }^{\text {vii }}$ Our data shows that expenditures for preventive measures increase when perceived disease pressure is increasing. 